\title{
Vaccination of Infants and Health Beliefs of Ultra-Orthodox Mothers
}

\section{Meital Simhi, Yana Shraga and Orly Sarid*}

Ben-Gurion University of the Negev, Department of Social Work, P.O. Box 653, Beer-Sheva, 84105, Israel

\begin{abstract}
Background: This study looked at mothers from the ultra-orthodox Jewish sector with the objective of obtaining information about their health beliefs and the behavior of these mothers regarding vaccination of their infants.

Methods: The study took place between April- December 2009. A snowball technique of sampling was chosen, a technique that is frequently used in studies conducted among minority groups. Inclusion criteria were mothers under thirty years old. The questionnaire was filled out about children whose ages ranged from 18 months to 24 months. We contacted 127 ultra-orthodox mothers, of whom $85(66.9 \%)$ consented to participate in the study and filled out the following questionnaires: Health Beliefs, Religious Beliefs, and demographic data. Vaccination behaviors were obtained by reviewing infant vaccination cards. Analysis of data included descriptive statistics, linear regressions and path-analysis model (SEM).

Results: Most ultra-orthodox mothers vaccinate their infants against Hepatitis B (HBV-97\%), polio (IPV-89.9\%), Diphtheria,Tetanus, Pertussis (DTaP-89.9\%), Haemophilus influenza b (Hib-89.9\%), pneumococcal infections (PCV13-87.3\%), Measles, Mumps, Rubella (MMR-88.6\%) and Varicella (Var-88.6\%). Linear regression analysis and the path analysis model revealed that a mother's vaccination behavior at a given time $(t)$ is influenced by her vaccination behavior at a previous time (t-1): for example, vaccination behavior up to age two months is the most powerful predictor of vaccination behavior at the age of four months.
\end{abstract}

Conclusions: It seems that the mothers' behavior toward vaccinating their infants at age two months is critical to the continued shaping and stabilization of a regimen of vaccinations over the following months.

Keywords: Infants' vaccination; Health belief model; Ultra-orthodox mothers

\section{Ultra-Orthodox Society}

The term ultra-orthodox expresses a religious-psychological reality in which an individual strongly desires to fulfill, in the most detailed and precise way, the commandments of God as expressed in the Jewish religious system [1]. The ultra-orthodox sector constitutes a Jewish minority in Israel and the Diaspora [2]. In Israel, the ultra-orthodox sector represents approximately nine percent of the Jewish population [3]. Ultra-orthodox society situates itself as a counter-culture opposed to the surrounding environment. This is reflected in an ideology and lifestyle of voluntary separatism [4,5] manifested in values, behavior, institutions and educational systems [2]. Collectivist values such as cooperation and mutual assistance are strongly stressed in this sector $[2,6]$. The ultra-orthodox community is very religious, resists change and innovation, and experiences a sense of spiritual and existential threat from secular society [7-9]. However, due to economic, social, political, and psychological factors, ultra-orthodox individuals take an active decision-making role in Israeli political and economic institutions $[2,10]$.

In scientific literature the ultra-orthodox Jewish sector is described demographically different from other groups in Israeli society due to early marriage, high fertility rates and poor economic conditions $[1,2]$.

Women in the ultra-orthodox community fill traditional roles such as the rearing and education of children and the maintenance of the home $[10,11]$. Because one of the principles of ultra-orthodox Judaism is a commitment to Bible study-which is considered the only legitimate field of study for men; ultra-orthodox women in many families have become breadwinners and fill a wide variety of roles in addition to their traditional roles. The father's role inultra-orthodox household is to exercise authority over his wife and children [11].
Previous studies reported low vaccination coverage and resistance to vaccine uptake among ultra-orthodox communities [12-14]. This has been attributed to religious objections to vaccination and a desire to avoid cooperation with government institutions $[13,14]$. The current study examines health beliefs of ultra-orthodox mothers regarding their infant vaccination. Previous studies have found that Health Belief Model (HBM) is useful in explaining adult vaccination health behavior [15-17]. HBM focuses on attitudes and beliefs of the individual about health behaviors. The model includes multiple aspects: susceptibility to perceived severity of health status, benefits, barriers to health behavior and environmental cues.

\section{Research Goals}

A. To examine health beliefs among ultra-orthodox Jewish mothers regarding infant vaccinations as recommended by the Ministry of Health.

B. To examine the behavior of ultra-orthodox Jewish mothers regarding the practice of vaccination.

C. To examine the relationship between health beliefs and vaccination behavior of ultra-orthodox Jewish mothers.

*Corresponding author: Orly Sarid, Ben-Gurion University of the Negev, Department of Social Work, P.O. Box 653, Beer-Sheva, 84105, Israel, Tel: 086428138; Fax: 08-6472933; E-mail: orlysa@bgu.ac.il

Received October 15, 2013; Accepted November 16, 2013; Published November 20, 2014

Citation: Simhi M, Shraga Y, Sarid O (2013) Vaccination of Infants and Health Beliefs of Ultra-Orthodox Mothers. J Vaccines Vaccin 5: 213. doi: 10.4172/21577560.1000213

Copyright: @ 2013 Simhi M, et al. This is an open-access article distributed under the terms of the Creative Commons Attribution License, which permits unrestricted use, distribution, and reproduction in any medium, provided the original author and source are credited. 


\section{Methods}

\section{Data collection}

Data were collected using a snowball technique of sampling. This technique is frequently used in studies conducted among minority groups $[18,19]$. The ultra-orthodox Jewish sector is a closed community in which members make decisions according to the leaders and spiritual authorities of the community $[11,12]$. This sampling method allows for the use of authority figures in the community to identify and recruit study participants. In the current study 12 women in key positions within the ultra-orthodox community were asked to assist in identifying study participants. In addition to locating the mothers, the purpose of the study was explained to them, they were asked to give their consent to participate in the study, and were asked to participate in a short interview. It was clarified to all participating mothers that the questionnaire is anonymous, and that they could withdraw their participation in the study at any time. Completion of the questionnaire took 40-60 minutes. Altogether, 127 ultra-orthodox mothers were contacted, of whom $85(66.9 \%)$ consented to participate in the study and filled out the questionnaire. The percentage of mothers contacted who refused to participate in the study $(33.1 \%)$ corresponded to the response of ultra-orthodox study participants described in the literature using a similar technique in Israel [18]. The data collection took place between April- December 2009.

The study received the approval of the Ethics Committee of BenGurion University in the Negev. All participants who expressed their consent to participate in the study signed an informed consent form.

\section{The sample}

A convenience sample included 85 ultra-orthodox mothers living in ultra-orthodox communities in the center and south of Israel. Ultraorthodox women displayed high fertility rates, up to seven children. The timing of childbearing among ultra-orthodox mothers is before the average age of 24 years old [20]. Therefore inclusion criteria were mothers under thirty years old. The questionnaire was filled out about their child whose age ranged from 18 months to 24 months.

\section{Research tools}

1. Health Beliefs Questionnaire: is based on an existing questionnaire, found to be valid and reliable, which examined health beliefs about receiving vaccines [15]. The Questionnaire consists of five sub-scales. Mothers were asked to rate the statements in all sub-scales on a five-point Likert scale ( $1=$ totally disagree, $5=$ totally agree), and indicate the extent to which each statement is relevant in their opinion.

A. Perceived barriers refer to costs (e.g., time, money) as well as psychological costs associated with behavior such as pain, anxiety, threat, and uncertainty involved in receiving the vaccine. In the current study five vaccination-related statements were presented (e.g., "The vaccine given to my infant has unpleasant side effects"). Cronbach's alpha 0.7.

B. Perceived susceptibility -refers to the likelihood that a mother believes that her child is in danger of becoming ill as a result of vaccination. Three vaccination-related statements were examined in this study (e.g., "I think that the infant has a chance of getting sick because of the vaccine"). Cronbach's alpha $=0.7$.

C. Perceived severity-refers to the likelihood that the mother believes that not receiving the vaccination will harm the infant. It was assessed with six vaccination-related statements (e.g. "If the infant does not receive the vaccine and develops the illness, it will be difficult for him to function"). Cronbach's alpha=0.7

D. Perceived benefits refer to the advantages of recommended health behavior in prevention of disease. In the current study it was tested using one statement ("Vaccinations prevent the diseases they are designed to prevent").

E. Effects of social cues refer to beliefs about source of information and the manner in which it is obtained. In the current study this aspect was tested using three closed questions that explored the source and method of obtaining information (e.g., "What is the most effective way for you to get information about vaccines?").

2. Religious Beliefs Questionnaire [21,22]. The questionnaire consists of three sub-scales: Definition of religiosity consists of six items ranging from "ultra-orthodox" to "not at all religious."

3. Health behaviors regarding vaccination were based of the infant's vaccination card from TipatChalavor the mother's selfreport. In Israel, systematic and orderly vaccination is delivered universally to child populations by TipatChalav (Health and Development Center for Infants) [23,24]. Adhering to the vaccinations regimen signified mothers' vaccinations behaviors: HBV (Hepatitis B) is administered by intramuscular injection three times: at birth, at one month and at six months; IPV (polio) vaccine is administered by intramuscular injection: at two months, at four months, at six months and at one year; DTaP (Diphtheria,Tetanus, Pertussis) vaccine, is administered by intramuscular injection: at two months, at four months, at six monthsand at one year; Hib (Haemophilusinfluenzae b), is administered by intramuscular injection: at two months, at four months, at six monthsand at one year; PCV13 (pneumococcal infections), is administered by intramuscular injection: at two months, at four months and at one year; MMR (Measles, Mumps, Rubella) and Var (Varicella-chicken pox) are administered by subcutaneous injection once at the age of one year; and HAV (Hepatitis A), is administered by intramuscular injection twice during the second year of the child's life: at 18 months and at 24 months $[23,24]$.

Rota (Rotavirus) was added to the vaccination regimen in 2010 and therefore was not included in the vaccine behaviors of our participants.

4. Breastfeeding- was examined with one question which asked the mother to specify the number of months she breastfed this child without making use of supplements.

5. Demographic data was reported by mothers and included age, education, ethno-cultural origin of the mother and her husband; economic status and employment of the mother and her husband; age and gender of the infant.

6. Availability of services: The mothers were asked how many days per week and for how many hours the TipatChalav clinic was open in their area of residence.

7. Accessibility of services at TipatChalav: Ascertained by two questions (e.g., "I find it difficult to get to the clinic because of the distance"). The choice of answers was dichotomous (i.e., yes / no). 


\section{Data analysis}

Data analysis was performed using statistical software SPSS 19.0(SPSS, Chicago, IL). Demographic variables of mothers, fathers and infants are calculated using descriptive statistics. Mean values for the Religious Beliefs Questionnaire were calculated and compared between mothers from different sects using one way ANOVA. These variables comprised the independent variables.

To answer the first research goal, mean values of Health Beliefs subscales were calculated and served as confounding variables. Availability and accessibility of health clinics were assessed.

To examine the second research goal, adherence to the regimen of vaccinations was calculated for each vaccine and is presented in numbers and percentages. Indices of vaccination behaviors were calculated and served as the dependent variables. Indices were based on the sum total of vaccines given at any point in time. Points in time were calculated in accordance with the recommendations of the Ministry of Health with regard to the desired provision of the vaccine in the first two years of life.

To examine the third research goal, the associations between the sub-scales of health beliefs and the vaccine indices were conducted using Pearson correlations. Subsequently, linear regression models were constructed: the demographic variables, health beliefs, duration of breastfeeding, and vaccine indices at earlier points in time were inserted as predicting variables. Finally, SEM was performed to predict the impact of independent and cofounding variables on vaccination behavior.

The alpha level of significance was set to .05 .

\section{Results}

\section{Demographic characteristics}

Mothers' average age is 26.74 years $(\mathrm{SD}=2.07)$, not shown in the table. Table 1 shows that the vast majority of mothers are married (97.6\%). Twenty percent of the mothers have a high school education, $46 \%$ have a post-high school education and $34 \%$ have a university education. Mothers working outside the home constitute $81.2 \%$ of the sample, and the rest are housewives. An above-average economic situation was reported by $3.6 \%$ of participants, $48.2 \%$ reported an average economic situation, and $48.2 \%$ reported a below-average one (Table 1).

All mothers described themselves as ultra-orthodox. Twenty-seven (32\%) identified themselves as ba'aleiteshuva (returnees to religion), while fifty-eight (68\%) were raised in ultra-orthodox homes.

Mothers reported of their husbands the following details: an overwhelming majority of husbands (91\%) are natives of Israel, and the rest were born in Asia and Africa. Nine husbands (10.6\%) have primary school education, twenty-five (29.4\%) have secondary education, fortysix $(54 \%)$ have post-secondary education, and five (6\%) have college education. More than one-third of the men (38\%) work outside of their home, while the rest of the husbands (62\%) are yeshiva students.

More than half the infants in the study were male $(56.5 \%)$. The average age of the toddlers was eighteen months with a standard deviation of five months. Nearly half the toddlers were firstborn (49.4\%), more than a third were second-born (36.6\%) and the rest were third-born. Most mothers (90\%) stated that the child had no prior illnesses.

\section{Mothers' health beliefs}

The findings presented in Tables 2 and 3 indicate that mothers believe that severity of health condition without vaccination is high. They believe that vaccines afford their infant health benefits, do not trigger high susceptibility and have few barriers. Most of the mothers (95.3\%) received an oral explanation from TipatChalav medical staff regarding vaccines.

Availability and accessibility of clinics were noted as possible confounding variables. TipatChalav clinics were opened an average of $4.28 \pm 1.26$ days per week. The vast majority of mothers $(96.5 \%)$ reported that it was "not difficult to reach the clinic due to distance."

\section{Breastfeeding}

Most mothers (88.2\%) reported that they breastfed their infants. Breastfeeding duration was normally distributed with an average duration of 8.4 months ( $\mathrm{SD}=6.02$ months).

\section{Behavior of mothers in regards to vaccination}

In Table 4 we see that most mothers maintained a regular vaccination regimen. We constructed indices based on the sum total of vaccines given at the age of two months, at four months, at six months, at one year and vaccinations given from age one to two.

In Table 5 we can see decrease in vaccination behavior in the second year.

The correlations between indices of vaccination during the first and second years are presented in Table 6 .

\begin{tabular}{|l|l|l|}
\hline Variables & Values & $\mathbf{N}(\%)$ \\
\hline Country of Origin & Israel & $76(89.4)$ \\
& Asia and Africa & $6(7.1)$ \\
& Europe & $3(3.5)$ \\
Ethnic background & Sephardic & $59(69.4)$ \\
& Ashkenazi & $26(30.6)$ \\
Marital Status & Married & $83(97.6)$ \\
& Divorced/Widowed & $1(1.2)$ \\
& High school & $17(20)$ \\
Occupation & Post-high school & $39(46)$ \\
& College & $29(34)$ \\
& Housewife & $16(18.8)$ \\
Economic status & Teacher & $51(60)$ \\
& Clerical and Sales & $18(21.2)$ \\
& Above average & $3(3.6)$ \\
& Average & $41(48.2)$ \\
& Below average & $41(48.2)$ \\
\hline
\end{tabular}

Table 1: Demographic characteristics of mothers Numbers (percent).

\begin{tabular}{|l|l|l|}
\hline Components of Model & $\begin{array}{l}\text { Average (Standard } \\
\text { Deviation) }\end{array}$ & Minimum-Maximum \\
\hline Barriers to health behaviors & $9.11(2.94)$ & $5-18$ \\
\hline Perceived advantages & $4.11(0.93)$ & $1-5$ \\
\hline Perceived susceptibility & $6.04(2.47)$ & $3-13$ \\
\hline Perceived severity & $16.27(3.30)$ & $7-24$ \\
\hline
\end{tabular}

Table 2: Health beliefs regarding vaccines (Means and standard deviations).

\begin{tabular}{|l|l|l|}
\hline Variable & Value & $\mathbf{n}(\%)$ \\
\hline Information delivery & Yes & $81(95.3)$ \\
& No & $4(4.7)$ \\
\hline Method of information & Written explanation & $36) 42.3)$ \\
delivery & Oral explanation & $49(57.7)$ \\
\hline Source of information & Family members & $4(4.8)$ \\
& Doctor or nurse & $81(95.2)$ \\
\hline
\end{tabular}

Table 3: Effect of social cues on health beliefs about vaccines Numbers (percent) 
Citation: Simhi M, Shraga Y, Sarid O (2013) Vaccination of Infants and Health Beliefs of Ultra-Orthodox Mothers. J Vaccines Vaccin 5: 213. doi: 10.4172/2157-7560.1000213

Page 4 of 6

\begin{tabular}{|c|c|c|c|}
\hline $\begin{array}{l}\text { Type of } \\
\text { Vaccination }\end{array}$ & $\begin{array}{l}\text { Mothers who gave } \\
\text { full vaccination } \\
\text { regimen }\end{array}$ & $\begin{array}{l}\text { Mothers who } \\
\text { gave partial } \\
\text { vaccination } \\
\text { regimen }\end{array}$ & $\begin{array}{l}\text { Mothers who gave } \\
\text { no vaccines }\end{array}$ \\
\hline $\begin{array}{l}\text { HBV } \\
\text { Hepatitis B }\end{array}$ & $78(97)$ & $1(1.3)$ & 0 \\
\hline $\begin{array}{l}\text { IPV } \\
\text { Polio }\end{array}$ & 71 (89.9) & 8)10.2) & 0 \\
\hline $\begin{array}{l}\text { DTaP } \\
\text { Diptheria, Tetanus, } \\
\text { Pertussis }\end{array}$ & 71 (89.9) & $8(10.2)$ & 0 \\
\hline $\begin{array}{l}\text { Hib } \\
\text { Haemophilus } \\
\text { influenza }\end{array}$ & 71 (89.9) & $8(10.2)$ & 0 \\
\hline $\begin{array}{l}\text { PCV13 } \\
\text { Pneumococcal } \\
\text { infection }\end{array}$ & $69(87.3)$ & $10(12.7)$ & 0 \\
\hline $\begin{array}{l}\text { MMR } \\
\text { Measles, Mumps, } \\
\text { Rubella }\end{array}$ & 70 (88.6) & & $9(11.4)$ \\
\hline $\begin{array}{l}\text { Var } \\
\text { Varicella-Chicken } \\
\text { Pox }\end{array}$ & $70(88.6)$ & & $9(11.4)$ \\
\hline $\begin{array}{l}\text { HAV } \\
\text { Hepatitis A }\end{array}$ & $10(35.7)$ & $13(46.6)$ & $5(17.9)$ \\
\hline
\end{tabular}

Table 4: Behavior of mothers regarding provision of vaccines Numbers (percentage).

\begin{tabular}{|l|l|l|}
\hline Vaccination Indices & $\begin{array}{l}\text { Averages } \\
\text { (Standard Deviations) }\end{array}$ & Minimum-Maximum \\
\hline By age $2 \mathrm{~m}$ & $4.64(1.3)$ & $0-5$ \\
\hline At age $4 \mathrm{~m}$ & $3.70(1.03)$ & $0-4$ \\
\hline At age $6 \mathrm{~m}$ & $3.70(1.03)$ & $0-4$ \\
\hline At age $12 \mathrm{~m}$ & $4.96(2.18)$ & $0-6$ \\
\hline Between $12-24$ months & $2.27(1.28)$ & $0-4$ \\
\hline
\end{tabular}

Table 5: Indices of vaccines administered during the first two years of life.

\begin{tabular}{|l|l|l|l|l|l|}
\hline $\begin{array}{l}\text { Vaccination } \\
\text { Index }\end{array}$ & At age 2 $\mathbf{~ m}$ & At age 4 m & At age 6 m & At age 12 $\mathbf{~ m}$ & $\begin{array}{l}\text { At age 12- } \\
\mathbf{2 4} \mathbf{~ m}\end{array}$ \\
\hline At age $2 \mathrm{~m}$ & & $0.994^{*}$ & $0.978^{*}$ & $0.630^{*}$ & $0.480^{*}$ \\
\hline At age $4 \mathrm{~m}$ & & & $0.970^{*}$ & $0.630^{*}$ & $0.474^{*}$ \\
\hline At age $6 \mathrm{~m}$ & & & & $0.670^{*}$ & $0.520^{*}$ \\
\hline At age $12 \mathrm{~m}$ & & & & & $0.760^{*}$ \\
\hline
\end{tabular}

$P \leq 0.05$

Table 6: Pearson correlations between the indices of vaccination during the first two years of life.

Subsequently, linear regression models were constructed with the demographic variables, health beliefs, duration of breastfeeding, and vaccine indices at earlier points in time as predicting variables. The findings indicate that vaccination behavior by two months of age is the strongest predictor of vaccination behavior at the age of four months (beta $=0.59, \mathrm{p}=0.000$ ). Vaccination behavior at four months is the strongest predictor of vaccination behavior at six months (beta $=0.47$, $\mathrm{p}=0.006)$. Vaccination behavior at six months is the strongest predictor of vaccination behavior around the age of one year ( $b e t a=0.34, \mathrm{p}=0.017$ ). Vaccination behavior at age one year is the strongest predictor of vaccination behavior after the first year (beta $=0.60, p=0.000)$. A "cascade" of vaccination behavior in which adherence to the vaccine regimen at a point in time $(\mathrm{t}-1)$ is the best predictor of adherence to the regimen at $t$.

It is interesting to note that only at two months old vaccination behavior of mothers was predicted by father education (beta $=0.27$, $\mathrm{p}=0.029$ ).

In the regression model, there is only one "path" through which predictors contribute to the dependent variable, therefore to expand the analysis a path-analysis model (SEM) was constructed.

Figure 1 links demographic variables such as paternal education, mother's behavior regarding duration of breastfeeding, and barriers to providing vaccinations, to patterns of vaccination only at two months of age.

From the model we can see that vaccination behavior at four months is affected by vaccination behavior at the previous stage, that is, vaccinations up to age two months. Vaccination behavior at any stage is influenced by the mother's vaccination behavior at the preceding stage only. This model does not differ from the optimal model $(\mathrm{X} 2=22.6$ $\mathrm{df}=25 \mathrm{p}=0.597 \mathrm{RMSEA}=0 \mathrm{NFI}=0.972$ ).

\section{Discussion}

This study examined mothers from the ultra-orthodox Jewish sector with the objective of obtaining information about the beliefs and behavior of these mothers regarding vaccination of infants. The findings indicate that a high percentage of ultra-orthodox Jewish mothers carry out a careful vaccination regimen in accordance with the recommendations of the Ministry of Health. Our findings differ from findings presented by Muhsen et al. [24] who stated that a lower percentage $(65 \%)$ of ultra-orthodox children between the ages of

\section{Mother's Vaccination Behavior}

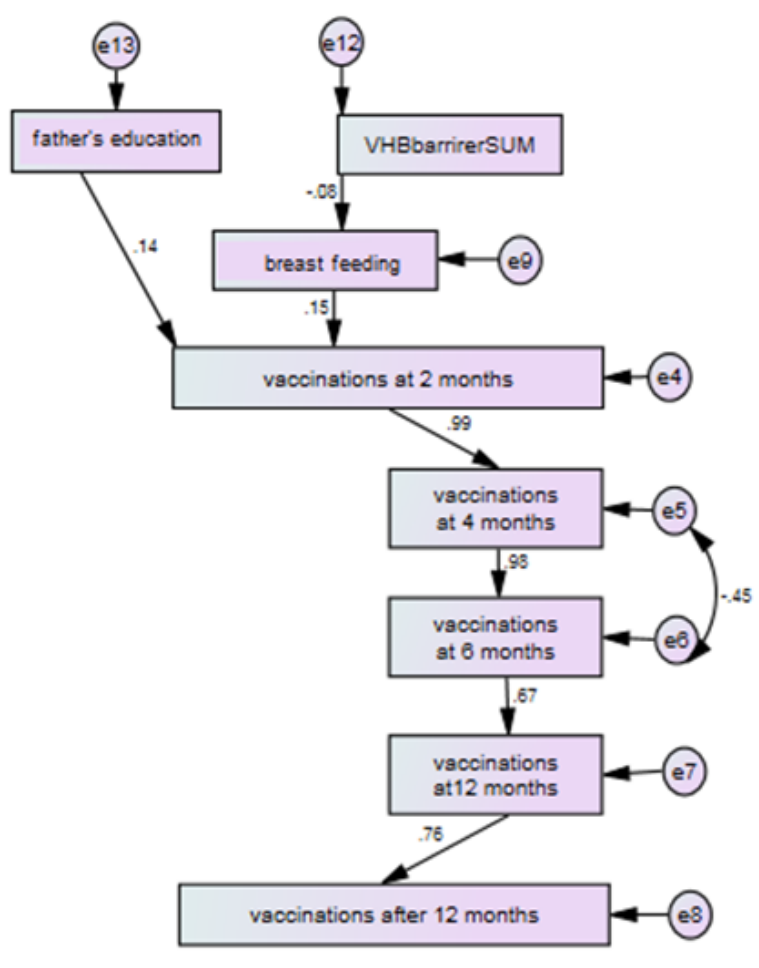

Chi $=21.878 \mathrm{df}=20 \mathrm{p}=.347$

RMSEA $=.033 \mathrm{NFI}=.972$

Figure 1: Vaccination behavior of ultra-orthodox mothers. 
2-5 was fully vaccinated in Jerusalem district. With regard to MMR, Stein-Zamir et al. [11] reported a vaccination coverage rate of $88.3 \%$ in ultra-orthodox communities, similar to the coverage found in our current study. A possible explanation for the high rate of vaccination of our participating mothers is having no more than three children, whereas mothers participating in Muhsen et al. [24] study had more than six children. A higher number of children might be related to low adherence to infant vaccination regimen among ultra-orthodox mothers due to the burden imposed on mothers taking care of many children.

Our results also reveal that the component of barriers was found to influence vaccination behavior. The more a mother regarded the vaccines as a threat to her infant's health the lower was the likelihood that she would vaccinate the infant. A possible explanation for this finding is provided in studies that analyzed mothers' opinions towards vaccination of their infants: negative personal experiences; a questioning of the value of vaccination; and a low level of trust in health professionals were all reported as fundamental to parental decision making about vaccination behavior [13]. Yet, in the SEM model the component of barrier did not directly affect prediction of vaccination behavior, but rather indirectly influenced behavior through the act of breastfeeding. Mothers who hold the belief that vaccines are risky for infants' health nurse their infants less. Path analysis (SEM) revealed that breastfeeding predicted vaccination behavior only at age two months.

Our findings showed that the mothers' behavior toward vaccinating their infant at age two months is critical to the continued shaping and stabilization of a regimen of vaccinations during the first and second year of the infant's life. The first vaccination behavior by two months is influenced by paternal education. The more educated the father was, it was more likely that the mother took the child to be vaccinated at the age of two months. A possible explanation is that more educated individuals possess a greater range of knowledge, resulting in an awareness of the importance of infant vaccinations. It should be emphasized that contrary to other findings [25], in our study maternal education did not predict vaccination behavior. It is possible that the authoritative status of the father in the ultra-orthodox Jewish family also affects the behavior of ultra-orthodox mothers in the area of child health maintenance.

Another finding pointed to a low vaccination behavior of participating mothers against Hepatitis A. Only one-third of the infants were vaccinated against this virus. A possible explanation for this low vaccination rate is the average age of the children in the current study, being 18 months. We cannot tell from our data if the mothers refused to vaccinate their infants or simply did not yet have time to vaccinate them with this specific vaccine. A follow-up study tracking children up to 24 months could provide data to answer this question.

Limitations of the study should be noted. First, we used snowball technique to recruit mothers. This sampling design is subject to selection bias. Second, the relatively small sample size and response rate (67\%) can also lead to bias in our findings. Using a self-report questionnaire to collect data on maternal breastfeeding may be subject to recall bias and social desirability bias. Self-report of religiosity may also be subject to social desirability bias. Yet, it should be noted that participating mothers knew that data collection is conducted anonymously.

\section{Recommendations}

Better understanding vaccination behavior of ultra-orthodox mothers can help healthcare professionals to provide culturally sensitive preventive treatments based on knowledge and awareness. Furthermore, an early collaboration with central figures in the ultraorthodox community and approaching mothers during pregnancy or at childbirth might increase adherence to health- behavior patterns with regard to vaccination of infants.

\section{Acknowledgement}

The study was conducted with the support of Roter foundation, Maccabi health services.

\section{References}

1. Friedman M (1991) The Haredi (Ultra-Orthodox) society; sources, trends and processes. The Jerusalem Institute for Israel Studies, Jerusalem.

2. Kaplan K (2003) Study of Haredi society in Israel: characteristics, achievements and challenges. Haredim in Israel: Integration without Assimilation? 224-277.

3. The Israel Central Bureau of Statistics (2011) The Statistical Yearbook 62.

4. Caplan $\mathrm{K}(2001)$ The media in Haredi society in Israel. Kesher 30: 18-31.

5. Simon RJ (1978) Continuity and change: A study of two ethnic communities in Israel. Cambridge: Cambridge University Press.

6. Laufer G (1988) The essence and spirit of counseling Haredi parents Counseling Haredi parents 166-180.

7. Gumbo R, Shwartz S (1989) A comparative perspective of the value system of young Haredi women. Megamot 32: 332-362.

8. Grylak M (2002) The Haredim Jerusalem: Keter (in Hebrew).

9. Sharot S (1996) Traditional, modern or postmodern? Recent religious developments among Jews in Israel. 118-133.

10. Levi A (1998) Hacharedim, Jerusalem: Keter.

11. Stein-Zamir C, Zentner G, Abramson N, Shoob H, Aboudy Y, et al. (2008) Measles outbreaks affecting children in Jewish ultra-orthodox communities in Jerusalem. Epidemiol Infect 136: 207-214.

12. Henderson L, Millett C, Thorogood N (2008) Perceptions of childhood immunization in a minority community: qualitative study. J R Soc Med 101 244-251.

13. Ben Natan M, Aharon O, Palickshvili S, Gurman V (2011) Attitude of Israeli mothers with vaccination of their daughters against human papilloma virus. $J$ Pediatr Nurs 26: 70-77.

14. Nexøe J, Kragstrup J, Søgaard J (1999) Decision on influenza vaccination among the elderly. A questionnaire study based on the Health Belief Model and the Multidimensional Locus of Control Theory. Scand J Prim Health Care 17: 105-110.

15. O'Reilly FW, Cran GW, Stevens AB (2005) Factors affecting influenza vaccine uptake among health care workers. Occup Med (Lond) 55: 474-479.

16. Blue CL, Valley JM (2002) Predictors of influenza vaccine. Acceptance among healthy adult workers. AAOHN J 50: 227-233.

17. Rier DA, Schwartzbaum A, Heller C (2008) Methodological issues in studying an insular, traditional population: a women's health survey among Israeli haredi (ultra-Orthodox) Jews. Women Health 48: 363-381.

18. Panacek EA, Thompson CB (2007) Sampling methods: selecting your subjects. Air Med J 26: 75-78.

19. Bystrov E (2012) The second demographic transition in Israel: One for all? Demographic Research 27: 261-298.

20. Bar-Lev, M. and Kedem, $P(1989)$ AliyatHanoar Students in Religious Institutions (Research Report), Ramat-Gan, Bar Han University (Hebrew)

21. Ben-Meir Y, Kedem P (1979) A measure of religiousness for the Jewish population in Israel. Megamot 24: 353-362.

22. Ministry of Health (2004) Guidline for preventive treatment for infants children and adolescences.

23. Ministry of Health (2004) Immunizations for babies and children. 
Citation: Simhi M, Shraga Y, Sarid O (2013) Vaccination of Infants and Health Beliefs of Ultra-Orthodox Mothers. J Vaccines Vaccin 5: 213. doi: 10.4172/2157-7560.1000213

Page 6 of 6

24. Muhsen K, Abed El-Hai R, Amit-Aharon A, Nehama H, Gondia M, et al. (2012) Risk factors of underutilization of childhood immunizations in ultraorthodox Jewish communities in Israel despite high access to health care services.

Vaccine 30: 2109-2115.
25. Leask J, Chapman S, Hawe P, Burgess M (2006) What maintains parental support for vaccination when challenged by anti-vaccination messages? A qualitative study. Vaccine 24: 7238-7245. 